fusion. This is subject to great variety, and it seems almost impossible to say beforehand, in any given case, whether belladonna will improve the sight or not; it must be made a matter of experiment. If it does improve the sight, it affords strong presumptive evidence that it is a case of cataract; but it is not safe to infer that cataract does not exist where belladonna increases the confusion. Shortness of sight almostinvariably attends cataract in its early stages, and is nerer assisted by concave glasses. Powerful magnifiers are the only form of glass that assists patients thus afflicted, and these only for a short time, and in some cases. Wherever a patient complains of very short sight that is not aided by concave glasses, cataract may be suspected. Musce volitantes not unfrequently accompany the various stages of cataract, being most obvious during the early stage, and often disappearing altogether after a successful operation. They indicate some change in the vitreous humour, or some congestion of the globe, but they do not prevent ultimate restoration of sight. Cataract usually forms without pain, and, when complete and of ordinary density, prevents all vision except perception of light.

Such are the principal subjective symptoms; we may now pass on to the consideration of the objective symptoms. Something may be gathered from observing the manner of the patient. He peers about as if he were striving to penetrate through a mist, and at the same time he shades his eyes from the light. In this respect his manner strongly contrasts with an amaurotic patient. On examining the eye, the pupil is observed to be perfectly moveable and active, which is very rarely the case in amaurosis in the early stage; and where the opacity is marginal and posterior, it is almost, if not quite, impossible to discover it except when the pupil is fully dilated; and in all cases of doubt and difficulty this should be done. The quickest and readiest mode of accomplishing this is by dropping into the eye a solution of the sulphate of atrophine, of the strength of a grain to half an ounce of distilled water. The effect generally takes place in about half an hour. The various appearances that the lens takes on in the different stages and different forms of cataract $I$ have already described in giving the history of the development of cataract, and further mention of them would only involve useless repetition. It is only in the early stage that difficulty is likely to be experienced in diagnosing cataract, and it is of great importance, both for your own credit and for the sake of your patient, to form a correct opinion, and no available means should be neglected in order to avoid error.

There are two conditions that are liable to be confounded with cataractous opacity of the lens: the one is a curious grey discoloration of the humours that often occurs in advanced age, and to an inexperienced eye very wuch resembles cataract; and the other is glaucomatous opacity, following disease of the globe. In the first of these cases the sight is not impaired, and therefore none but the rash, the inconsiderate, and the ignorant would volunteer an opinion that cataract exists; and yet I have known several instances in which this has been done, to the serious and unnecessary alarm of the patient, the discredit of the surgeon, and the ultimate injury of the entire profession. In glaucomatous opacities, or those dull, greenish discolorations of the humour that accompany or follow some forms of diseased globe, the previous history is a valuable guide. A sluggish state of the pupil, a dilated state of the sub-conjunctival vessels, all contraindicate true cataract. Moreover, the opacity is shifting, according to the position in which the light falls, whereas the opacity of the cataract, even in its earliest stage, is fixed.

As a further means of ascertaining the existence of cataract, the catoptric test is mentioned by most writers, though $I$ think its value is not very great. If a lighted candle is held opposite the eye, three images are observed, two upright, and one inverted. The most anterior of these is always bright and distinct, and is formed by the cornea. The middle is inverted, and very small, and is formed by the posterior surface of the crys talline lens. The posterior is deep and always indistinct, and is formed by its anterior surface. On moving the candle, the two erect images move with it, the inverted image in the opposite direction. Even in the early stage of cataract, the inverted image is lost. Wherever the three images can be distinctly seen unaltered, we may be certain that no opacity exists in the lens, and this fact seems to me to constitute its chief value as a test. In a case, for instance, that has been pronounced by some authority to be cataract, if the three images can be seen, it sets the matter at rest at once, and gives an unerring negative to the previous opinion.

Recently another very powerful means of detecting lenticular opacities, even in their early stages, has been used. The oph. thalmoscope enables us to see minute and faint patches, such as the unassisted eye would search for in vain, and can hardly detect, after their presence, and situation, and size, have been indicated by this most valuable instrument. I shall hope, in a future lecture, to explain to you the form, the mode of using, and the capabilities of the ophthalmoscope; at present I limit myself to the statement of its great value in the early stage of cataract.

There are some peculiarities about the congenital and traumatic forms of lenticular opacity, which I propose to describe in the next lecture.

\section{MTLITARY MEDICAL PRACTICE IN THE} EAST.

By GEORGE PYEMONT SMITH, M.D., M.R.C.S., LICTCRER OY MEDICAL JURISPRCDENCE AT THE LEEDS SCHOOL OF MIEDICINE. (Concluded from page 582.)

THE general mismanagement from which our hospitals at Scutari have suffered has become too notorious to require any notice; but a little investigation into the causes of that mismanagement, and the minutiæ of the medical deficiencies, may not be without its advantages. It appears that the first cause of all the evil, as well in the military arrangements generally as in the purely medical department, has been the adherence in time of war to laws and regulations made for their management in peace and under ordinary circumstances. A small pamphlet, published by authority, and entitled "Regulations for the Management of Barrack Hospitals at Home and Abroad," has been, I believe, the source of much evil at Scutari. These "Regulations" are well adapted, on rigidly economical principles, for the ordinary control of a barrack hospital with twenty or thirty patients, in all its minutix; but the folly of attempting to govern the Scutari hospitals, with their 4000 or 5000 inmates, by the same means, would, one might have thought, have been too obvious ever to be attempted.

At the end of November the Barrack Hospital, with 2000 patients, had only one small surgery, with a stock of drugs of the most limited variety, and in quantity so small that deficiencies were daily and hourly occurring in all those in common use. The assistant-surgeons, each in charge of from 80 to 100 patients, had all their medicines to compound with scarcely any of the ordinary requisites for such operations. (Scutari never possessed a single pill-machine kefore the beginning of March, 1855.) It became quite necessary, before writing out a prescription, to ascertain what drugs were to be found in the surgery, and it was soon evident to me that the only way of ensuring my patients getting their medicines was to administer them all myself, and this I regularly did all the time I was there.

With diarrhcea and sickness as the most common complaints in the hospital, there was no chalk, prussic acid, oil of cinnamon, creasote, or bismuth. These drugs are not comprised in the list in the "Regulations," and therefore no supply of them had ever been forwarded. The following drugs were also in such small quantities that scarcely a day passed over without their becoming exhansted, and often for days together no further supply was produced :-Aromatic confection, compound chalk powder, compound chalk with opium, tincture of squills, compound tincture of camphor, ipecacuanha wine, \&c; oxymels and syrups were never supplied. There were never any phials provided for the administration of medicines, but we were obliged to have recourse to wine bottles, or, when we could get hold of them, empty drug-bottles.

Some attempts to improve this state of affairs were made in December. In the first week the surgery was closed, and two others in more convenient situations were opened; a third was added in Jantiary, and in February there were four surgeries. About the middle of December a quantity of prepared chalk, with some other drugs, whose supply had failed, were procured from Constantinople; the chalk was, however, soon exhausted again. The last week in December dispensers were appointed to the different surgeries. A staff of dispensers or apothecaries, with a number of assistant-surgeons, were hurriedly ordered off from England to Seutari on Sunday the 10th December, (Parliament met on the 12th.)

The medical staff is commonly recruited from young men who have just left the schools and passed their examinations, and in times of peace this means answers well enough; but when from the emergencies of the occasion the number of medi- 
cal men in the army had to be doubled, one might have supposed the evil that would result from observing the same regulations, and the advisability of making some deviation from established rules to secure the services of medical men of some experience and standing in the profession, would have been obvious even to official intellect. On similar occasions previously it has been customary to give practitioners of experience, who may be willing to serve in the army, first or second class appointments; but during the present war those in power (after the true style of official routine) deemed it wiser and more expedient to make no deviation from established rules; and not only was every man entering the service obliged to go in by the lowest door as assistant-surgeon, but in the cases that did occur of experienced practitioners, who were anxious to give their services for a limited time in any capacity that would make them useful, the appointment of assistant-surgeon was refused to men under forty years of age, on the plea that they were too old for the service.

The result of this has been that the whole treatment of the sick soldiers has been placed in the hands of a set of youths just come from the schools. This statement, however, requires some qualification, for, with characteristic obtuseness; the only department they were more likely to prove successful in than their seniors-viz., that of operative surgery, was reserved exclusively for the superior army surgeons; for I contend, that when skilful and experienced operating surgeons cannot be found, the student newly arrived from the dissecting-room and hospital, before his anatomy has had time to grow rusty, is much more likely to prove a successful operator than the army surgeon of from forty to fifty, who, in the routine of his barrack practice, has not had opportunities of either seeing or practising operative surgery.

In any account that is given of the number of medical men attached to the hospitals, and the proportion they bear to the patients, it must be borne in mind that at least one-fourth of the medical men, and those the most experienced, have nothing whatever to do with the medical treatment of the patients, but are engaged in superintending official duties, and another fourth are disqualified by illness from any work whatever. I find, from my note-book, that on the 17th of January, out of forty-six surgeons attached to the Barrack Hospital at Scutari, twelve were on the sick list. The effect of these considerations will of course be, that the medicil men in actual service will each of them have under their care double the number of patients that a bare statistical enumeration would assign to them.

Another great source of evil is the constant changes that take place in all departments of the medical staff. During the three months I was at Scutari we had five urincipal medical officers, and the changes were nearly as frequent in the lower departments. For the slightest cause an assistant-surgeon was removed from one division to another, and sometimes, in the course of a week, the men in one ward had their medical attendant changed three times. On other occasions the medical officers were ordered to hold themselves in readiness for a change of duties, which change was delayed from day to day, and then perhaps indefinitely postponed. The effect of these proceedings was entirely to prevent that intimate acquaintance with a patient and his disorders upon which a proper treatment can alone be based, and frequently led to the use of mere temporary palliative measures, instead of commencing a course of treatment calculated in time to effect a radical cure, but which the prescriber knew he would not have the opportunity of carrying out.

The deficiencies in the cooking apparatus were, to some extent, supplied by Miss Nightingale's staff; but one very great evil was beyond their powers to remedy. No means were provided for cooking meat, except by boiling it, and although boiling was undoubtedly the most likely to make Scutari beef or goat's-flesh digestible, it is easy to imagine how the daily recurrence of broth and boiled meat would pall upon the most healthy appetite. What, therefore, must be its effects upon the fastidious palate of an invalid? Upon mentioning this subject to those who were likely to have the power of getting the grievance remedied, I was told that it always had been a source of complaint in barrack hospitals, and the inference was drawn that therefore it always would be. The irregularity of the hours at which the meals were served, must have had a very prejudicial effect: It often happened that the men got their breakfast before nine o'clock, and their dinner was not produced before four, sometimes five, and often then with the meat in a raw state. For a long time there was no supply of knives and forks, and the portions for the men were divided by the orderlies tearing them piecemeal with their fingers.
In the purveyor's department, beds, blankets, shirts, flannels, \&c., were frequently, wanting, medical comforts fell short of the required supply, and even so late as February, when port wine was ordered in cases of dysentery and diarrhoea as an astringent and tonic restorative, the noxious stimulant, Marsala, was substituted for it.

These are, no doubt, some of the causes that contributed to produce the frightful mortality in the months of December, January, and February.

The celebrated manifesto of Dr. Hall against chloroform had not much attention paid to it at Scutari. I had been accustomed to the use of chloroform, but certainly had never seen it given to the extent that it was employed there. An operation was never commenced bcfore the patient was fully under the influence of chloroform Where a patient can, with out injury to health or life, be brought into this state, (and I must acknowledge that $I$ did not see or hear of any one dying under the influence of chloroform, and this extreme action did not prove so injurious as I expected, ) it affordis great facilities to an inexperienced operator, and prevents any necessity for hurrying an operation.

Generally speaking, at Scutari, the patient was, by means of chloroform, brought into the condition of a dead body, and then it was not an operation, but a dissection that was performed.

In one of my Russian cases (No. 24), where a flap amputation of the leg was performed, the anterior tibial artery had re. tracted within its sheath, and there was some difficulty and delay in securing the vessel; the parts were brought together by three or four sutures, and the patient sent to his ward. About three hours afterwards I visited him for the purpose of completing the dressing. On uncovering the limb and touching: the stump, there was an immediate gush of arterial blood. My first idea was that the ligature had not been securely placed on the anterior tibial artery, and that it was that vessel which was furnishing the hæmorrhage. Situated as I was, with only the assistance of orderlies and dusk approaching, it would have been nearly impossible to have arrested such a hæmorrhage in time to have prevented a fatal result. I went off forthe surgeon of the division, divided the sntures, and on opening the stump, to my great relief, found the hrmorrhage proceeding from a large vessel upon the open surface of the flap. Placing the thumb upon it sufficed to stop the hæmorrhage until I got a tenaculum and ligature, which were fortumately in my pocket; the vessel was properly secured, and the stump dressed and bandaged, before any further assistance arrived.

This vessel had not been observed during the operation, and no attempt had been made to secure it. If the dressing had been completed after the operation, no doubt hæmorrhage would have occurred during the next twenty-four hours, and to such an extent that the man must have died before anything could be done to arrest it

Must not the absence of any flow of blood from this artery during the operation be attributed to the general effect of chloroform upon the system?

Experimexts on the Heart.-The interest connected with the young man (E. A. Groux), whose heart and pericardium are exposed to view, as described in last week's LANCET, seems to increase every day. As a large sum of money is required at each school, something like three guineas, before any examination or stethoscopic experiments as to the sounds of the heart are permitted, it may be convenient to inform old pupils of St. Thomas's, that they may have an opportunity of seeing him exhibited to-day (Saturday, 30th). St. Bartholomew's men also, we believe, the same day, at an earlier hour. When it is remembered that the singular want of development of the bones of the chest in this young man has been the subject of examination by committees of almost all the academies in Europe-that he has been recently at Stockholm, where he was examined by the illustrious Retzius, as well as at Pesth, Prague, and Vienna, where he was subjected to experiment by Rokitansky - that he has visited all the other intermediate cities of Copenhagen, Berlin, Cracow, Munich, Strasburgh, Paris, and at each has been received with additional interest, - we believe our readers will feel grateful to us for reminding them of the opportunity of witnessing the phenomena for themselves, and making observations on the human heart during life. The young man goes back to Paris next week, as a committee is sitting there to investigate the case. He then leaves, we believe, for America. 